Polymer Journal, Vol. 39, No. 6, pp. 610-621 (2007)

(C) 2007 The Society of Polymer Science, Japan

\title{
Low-CTE Polyimides Derived from 2,3,6,7-Naphthalenetetracarboxylic Dianhydride
}

\author{
Masatoshi HASEGAWA ${ }^{\dagger}$ and Shunichi HORII \\ Department of Chemistry, Faculty of Science, Toho University, 2-2-1 Miyama, Funabashi 274-8510, Japan
}

(Received February 7, 2007; Accepted March 21, 2007; Published April 27, 2007)

\begin{abstract}
NTDA) showed high reactivity in the polymerization of polyimide precursors [poly(amic acid)s (PAAs)] with various aromatic and cycloaliphatic diamines with an exception of trans-1,4-cyclohexanediamine (CHDA). On the other hand, another isomer 1,4,5,8-NTDA did not allow the formation of high molecular weight PAAs. The poor reactivity of 1,4,5,8-NTDA is probably attributed to the more stable six-membered anhydride structure. The polyimide (PI) films derived from 2,3,6,7-NTDA with some diamines possessing stiff/linear structures, i.e., p-phenylenediamine (PDA), 4-aminophenyl-4'-aminobenzoate (APAB), and 2,2'-bis(trifluoromethyl)benzidine (TFMB) exhibited no distinct glass transitions on the dynamic mechanical thermal analysis or a considerably high $T_{\mathrm{g}}$ exceeding $400^{\circ} \mathrm{C}$, extremely low CTE values close to that of silicon wafer or lower, and relatively low degrees of water absorption simultaneously in addition to excellent thermal stability. A polyimide system derived from 2,3,6,7-NTDA and 4,4'-oxydianiline (4,4'-ODA) achieved a low CTE approximate to that of copper foil $\left(20.0 \mathrm{ppm} \mathrm{K}^{-1}\right)$ in spite of the presence of flexible ether linkages in the structure while retaining excellent film toughness (elongation at break $>80 \%$ ). The low CTE characteristics observed probably results from the longer naphthaldiimide mesogenic unit which acts more effectively for the imidization-induced in-plane orientation. The properties of 2,3,6,7-NTDA-based PIs were compared with those of PIs derived from a fixed diamine with different dianhydrides, i.e., pyromellitic dianhydride (PMDA) and 3,3',4,4'-biphenyltetracarboxylic dianhydride (s-BPDA) to elucidate the merits of the use of 2,3,6,7-NTDA. The results revealed that 2,3,6,7-NTDA is a useful monomer for lowering both CTE and water absorption and enhancing $T_{\mathrm{g}}$. [doi:10.1295/polymj.PJ2006234]

KEY WORDS Polyimides / 2,3,6,7-Naphthalenetetracarboxylic Dianhydride / 1,4,5,8-Naphthalenetetracarboxylic Dianhydride / Low Linear Coefficient of Thermal Expansion (CTE) / Low Water Absorption /
\end{abstract}

Polyimides (PIs) have been widely utilized in a variety of micro- and optoelectronic applications such as the substrates for flexible printed circuit (FPC) and tape automated bonding (TAB), buffer-coating films and interlayer dielectrics for LSI chips, high temperature adhesives, light wave guides for their combined excellent properties, i.e., high glass transition temperatures $\left(T_{\mathrm{g}}\right)$, high resistance to chemicals and radiation, relatively low dielectric constants ( $K$ or $\varepsilon$ ), and good mechanical properties. ${ }^{1-10}$ The advantages of PI materials are considerably high purity in the resins, simple production processes, and the ease of structural modifications through copolymerization using various commercially available monomers.

Recently, the demands of PIs for the FPC applications have been increasing more and more in the world. Particularly, adhesive-free PI film/Cu laminates (flexible copper clad laminates, FCCL) for FPC fabrications, where the solutions of PI precursors, poly(amic acid)s (PAAs), are directly coated onto a cupper foil, have an advantage in the view point of dimensional stability compared to FCCL using adhesives. In the adhesive-free FCCL fabrication process- es, the linear coefficients of thermal expansion (CTE) of PI layers must be precisely controlled to avoid some serious troubles arising from the CTE mismatching. However, in many cases, PI films have much higher CTE values in the film plane direction ranging $40-80 \mathrm{ppm} \mathrm{K}^{-1}$ than those of metal substrates (e.g., $17 \mathrm{ppm} \mathrm{K}^{-1}$ for cupper foil). This means that, when PI films were formed on a metal substrate via thermal imidization after the solution-casting of PAAs, the PI/metal laminates undergo thermal stress arising from the CTE mismatching during the cooling process from cure temperature to room temperature. Consequently it causes serious problems such as curling, cracking and detaching of the PI films. Therefore, considerable efforts for developing low-CTE PIs have been made. Systematic investigations on the structure-CTE relationship in various aromatic PI systems revealed that low-CTE PIs (as a temporal target, $\mathrm{CTE} \leq 20 \mathrm{ppm} \mathrm{K}^{-1}$ ) have unexceptionally linear/stiff PI chain backbones. ${ }^{11,12}$ A typical low-CTE PI film is known as s-BPDA/PDA polyimide derived from 3,3',4,4'-biphenyltetracarboxylic dianhydride (s-BPDA) and $p$-phenylenediamine (PDA). This PI

${ }^{\dagger}$ To whom correspondence should be addressed (Tel: +81-47-472-4960, Fax: +81-47-472-4960, E-mail: mhasegaw@ chem.sci.toho-u.ac.jp). 


\section{Dianhydrides}<smiles></smiles>

2,3,6,7-NTDA

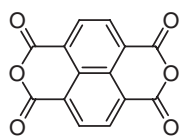

1,4,5,8-NTDA



s-BPDA

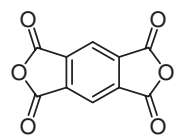

PMDA

\section{Diamines}

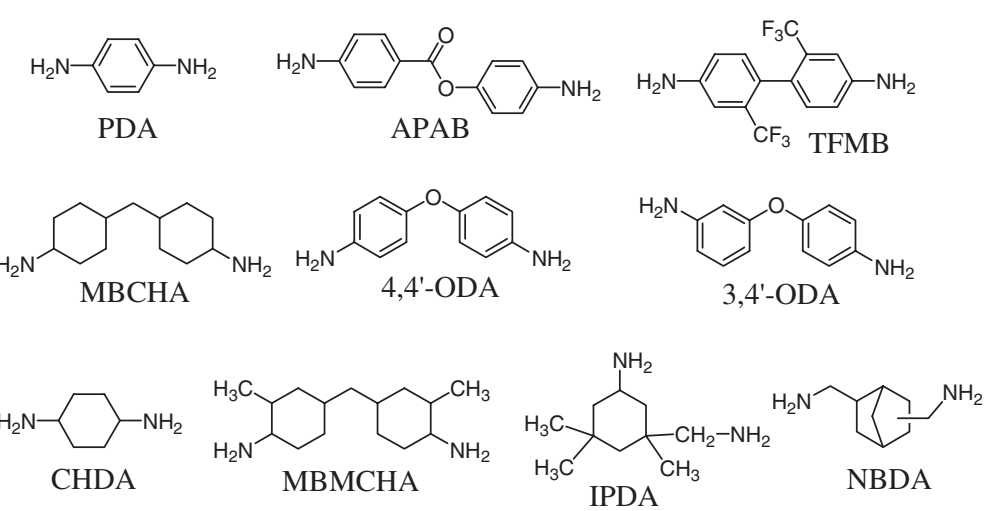

Figure 1. Molecular structures and abbreviations of monomers used.

film exhibits CTE values ranging $5-20 \mathrm{ppm} \mathrm{K}^{-1}$ depending on the film thickness and the processing conditions. ${ }^{13,14}$

The low CTE characteristics observed in some limited PI systems are closely related to a thermal imidization-induced in-plane chain orientation phenomenon. We have previously proposed a hypothesis for its mechanism where stiff/linear PI chain structures play a great role for liquid crystal-like interactions as a trigger for the self-orientation phenomenon. ${ }^{13}$

However, "rod-like" dianhydride monomers, which give stiff linear PI backbones effective for the imidization-induced in-plane orientation, are limited to pyromellitic dianhydride (PMDA), s-BPDA, and $p$ terphenyltetracarboxylic dianhydride (TPDA) ${ }^{15-17}$ whereas a variety of diamines with stiff/linear structures are known and commercially available. We have previously demonstrated that a para-ester-linked dianhydride, hydroquinone bis(trimellitate anhydride) (TAHQ) is also classified into the concept of rod-like monomers. ${ }^{18}$

Another important subject required for PI materials in FCCL is the dimensional stability against absorbed water or to decrease water absorption itself. It is accepted that polyimides are in general much easier to absorb water in air than polyesters. Such high water absorption originates from a high content of highly polarized imide groups. Accordingly, a further increase in the content of aromatic units is expected to cause a decrease in water absorption.

Naphthalenetetracarboxylic dianhydride (NTDA) can be a candidate monomer in achieving both of low CTE and low water absorption. The combinations of 1,4,5,8-NTDA and sulfonated diamines are known to give heat resistant proton-conductive membrance. ${ }^{19}$ However, commercially available 1,4,5,8NTDA consisting of thermodynamically stable sixmembered anhydride groups had very poor PAA polymerizability with any diamines although one-pot polycondensation can be allowed typically in a protic solvent such as $m$-cresol at elevated temperatures to form PIs directly. On the other hand, another isomer, 2,3,6,7-NTDA possessing five-membered anhydride rings is expected to show high reactivity no less than common dianhydrides, nonetheless, few papers have reported the film properties of the 2,3,6,7-NTDAbased PI systems in detail. ${ }^{20}$

The purpose of this work is to investigate the polymerizability and film properties of the 2,3,6,7-NTDAbased PI systems. The present paper reveals that 2,3,6,7-NTDA is a useful dianhydride monomer for reducing both CTE and water absorption of the resultant PI films. In this work, the film properties of the 2,3,6,7-NTDA-based PI systems were also compared with those of PMDA-based systems to discuss their merits.

\section{EXPERIMENTAL}

\section{Materials}

The molecular structures and abbreviations of the monomers used in this work are shown in Figure 1. 
M. HASEGAWA and S. HORII

Table I. Sources and conditions of pre-treatment and purification for monomers used

\begin{tabular}{|c|c|c|c|c|}
\hline Monomer & Source & $\begin{array}{c}\text { Solvent for } \\
\text { recrystallization }\end{array}$ & $\begin{array}{l}\text { Vacuum-drying } \\
\text { condition }\end{array}$ & $\begin{array}{c}\text { Melting point }{ }^{\mathrm{d})} \\
\left({ }^{\circ} \mathrm{C}\right)\end{array}$ \\
\hline 2,3,6,7-NTDA & JFE Chemical & - & $120^{\circ} \mathrm{C} / 24 \mathrm{~h}$ & 360 \\
\hline 1,4,5,8-NTDA & Aldrich & - & $120^{\circ} \mathrm{C} / 24 \mathrm{~h}$ & 451 \\
\hline PMDA & $\begin{array}{l}\text { Tokyo Chemical } \\
\text { Industry (TCI) }\end{array}$ & - & $150^{\circ} \mathrm{C} / 24 \mathrm{~h}$ & 287 \\
\hline s-BPDA & $\begin{array}{l}\text { Ube Industries } \\
\text { TCI }\end{array}$ & - & $200^{\circ} \mathrm{C} / 24 \mathrm{~h}$ & 300 \\
\hline PDA & TCI & Ethyl acetate & $50^{\circ} \mathrm{C} / 24 \mathrm{~h}$ & 142 \\
\hline APAB & Wakayama Seika & - & $50^{\circ} \mathrm{C} / 24 \mathrm{~h}$ & 185 \\
\hline TFMB & Central Glass & - & $50^{\circ} \mathrm{C} / 24 \mathrm{~h}$ & 184 \\
\hline CHDA & $\begin{array}{c}\text { Iwatani Industrial } \\
\text { Gases }\end{array}$ & - & $30^{\circ} \mathrm{C} / 24 \mathrm{~h}$ & 70 \\
\hline $4,4^{\prime}-\mathrm{ODA}$ & Wako Chemical & $\begin{array}{c}\text { Toluene/DMF } \\
(10 / 1, \mathrm{v} / \mathrm{v})\end{array}$ & $50^{\circ} \mathrm{C} / 24 \mathrm{~h}$ & 187 \\
\hline $3,4^{\prime}-\mathrm{ODA}$ & Wakayama Seika & - & $50^{\circ} \mathrm{C} / 24 \mathrm{~h}$ & 79 \\
\hline $\begin{array}{c}\text { MBCHA }^{\mathrm{a})} \\
\text { (cis/trans mixture) }\end{array}$ & $\begin{array}{l}\text { New Japan } \\
\text { Chemical }\end{array}$ & - & - & - \\
\hline trans-trans-MBCHA ${ }^{\mathrm{b})}$ & - & $n$-hexane & $30^{\circ} \mathrm{C} / 24 \mathrm{~h}$ & 62 \\
\hline $\mathrm{MBMCHA}^{\mathrm{c})}$ & Aldrich & - & - & -7 \\
\hline $\mathrm{NBDA}^{\mathrm{c})}$ & Mitsui Chemical & - & - & - \\
\hline
\end{tabular}

a) non-crystalline solid at room temperature. b) obtained by recrystallization of MBCHA (cis/trans mixture). c) colorless liquid at room temperature. d) determined from the endothermic peak temperatures in the DSC thermograms recorded at a heating rate of $5{ }^{\circ} \mathrm{Cmin}^{-1}$.

2,3,6,7-NTDA were kindly supplied by JFE Chemical Corp. Aromatic and cycloaliphatic diamines were kindly supplied from the following companies: APAB, (Wakayama Seika), TFMB (Central Glass), CHDA (Iwatani Industrial Gases), 4,4'-methylenebis(cyclohexylamine) (cis/trans mixture) (MBCHA, New Japan Chemical), and 2,5-(2,6)-bis(aminomethyl)bicyclo[2.2.1]heptane or norbonanediamine (NBDA, Mitsui Chemical). Other monomers were purchased from commercial sources. Purification procedures or pre-treatment conditions and melting points of the monomers used are listed in Table I. All the solvents used were dried with molecular sieves $4 \mathrm{~A}$ prior to use.

PI precursors, poly(amic acid)s (PAAs) were prepared as follows unless stated otherwise: the equimolar amount of dianhydride powder was gradually added into the $\mathrm{N}, \mathrm{N}$-dimethylacetamine (DMAc) or $\mathrm{N}$ methyl-2-pyrrolidone (NMP) solution of diamines at room temperature with stirring at room temperature for a prolonged period until the reaction mixture turns to a viscous/clear solution and the viscosities are stabilized. The detailed polymerization conditions and reduced viscosities of the PAAs obtained are shown in Tables II and III. In this paper, the chemical compositions of PI systems are abbreviated using monomer components as $\mathrm{Y} / \mathrm{Z}$ for homopolymers and $\mathrm{Y}_{1} / \mathrm{Z}_{1} ; \mathrm{Z}_{2}$ for copolymers $(\mathrm{Y}=$ dianhydride, $\mathrm{Z}=$ diamine components).
Table II. Polymerization conditions and inherent viscosities of PAAs in 2,3,6,7-NTDA systems

\begin{tabular}{ccccc}
\hline Diamine & Solvent & $\begin{array}{c}\text { Solid } \\
\text { content } \\
(\mathrm{wt} \%)\end{array}$ & $\begin{array}{c}\text { Reaction } \\
\text { period } \\
(\mathrm{h})\end{array}$ & $\begin{array}{c}\eta_{\text {red }} \\
\left(\mathrm{dL} \mathrm{g}^{-1}\right)\end{array}$ \\
\hline PDA & DMAc & $15 \rightarrow 5.2$ & 48 & 5.80 \\
APAB & DMAc & $15 \rightarrow 8.1$ & 72 & 2.21 \\
TFMB & DMAc & $15 \rightarrow 11.3$ & 68 & 2.15 \\
CHDA & DMAc & $12 \rightarrow 7.6$ & 96 & - \\
CHDA & DMAc & 7.5 & 96 & - \\
CHDA & NMP & $12 \rightarrow 8.4$ & 48 & - \\
Silylated CHDA & DMAc & $15 \rightarrow 6.5$ & 430 & - \\
Silylated CHDA & NMP & $15 \rightarrow 6.8$ & 260 & - \\
4,4'-ODA & DMAc & $15 \rightarrow 6.1$ & 20 & 6.35 \\
3,4'-ODA & DMAc & $15 \rightarrow 9.4$ & 47 & 2.64 \\
MBCHA (c/t mix) & DMAc & $15 \rightarrow 8.5$ & 26 & 1.94 \\
t,t-MBCHA & DMAc & 7.5 & 21 & 1.50 \\
MBMCHA (c/t mix) & DMAc & $15 \rightarrow 8.3$ & 24 & 2.00 \\
IPDA (c/t mix) & DMAc & $15 \rightarrow 12$ & 24 & 1.05 \\
NBDA & DMAc & $30 \rightarrow 16.2$ & 20 & 0.64 \\
MBCHA (c/t mix) 50 & DMAc & $15 \rightarrow 9.1$ & 143 & - \\
CHDA 50 & & & & \\
MBCHA (c/t mix) 50 & NMP & $15 \rightarrow 8.7$ & 240 & - \\
CHDA 50 & & & & \\
MBCHA (c/t mix) 60 & NMP & $15 \rightarrow 8.7$ & 74 & 1.12 \\
CHDA 40 & & & & \\
\hline
\end{tabular}

The PAA solutions were doctor-bladed on a glass substrate to form, then dried at $60^{\circ} \mathrm{C}$ for $2 \mathrm{~h}$ in an air-convection oven. The PAA films obtained were 
Table III. Polymerization conditions and inherent viscosities of PAAs in 1,4,5,8-NTDA systems

\begin{tabular}{lccccc}
\hline Dianhydride & Diamine & Solvent & $\begin{array}{c}\text { Solid } \\
\text { content } \\
(\mathrm{wt} \%)\end{array}$ & $\begin{array}{c}\text { Reaction } \\
\text { period } \\
(\mathrm{h})\end{array}$ & $\begin{array}{c}\eta_{\text {red }} \\
\left(\mathrm{dL} \mathrm{g}^{-1}\right)\end{array}$ \\
\hline $1,4,5,8-\mathrm{NTDA}$ & $4,4^{\prime}$-ODA & NMP & $15 \rightarrow 9.8$ & 160 & 0.284 \\
$1,4,5,8-\mathrm{NTDA}$ & TFMB & NMP & 25 & 144 & - \\
$1,4,5,8-\mathrm{NTDA}$ & MBCHA & NMP & $15 \rightarrow 10$ & 216 & - \\
$1,4,5,8-\mathrm{NTDA}$ & MBCHA & DMAc & 15 & 360 & - \\
$1,4,5,8-\mathrm{NTDA}$ & IPDA & NMP & 15 & 192 & - \\
NTDA 50 mol \% & MBCHA & NMP & $15 \rightarrow 8$ & 48 & - \\
6FDA 50 mol \% & & & & & \\
NTDA 30 mol \% & MBCHA & NMP & 15 & 24 & 0.265 \\
6FDA 70 mol \% & & & & & \\
NTDA 20 mol \% & MBCHA & NMP & 15 & 24 & 0.267 \\
6FDA 80 mol \% & & & & & \\
$\begin{array}{l}\text { NTDA 10 mol \% } \\
\text { 6FDA 90 mol \% }\end{array}$ & MBCHA & NMP & 15 & 24 & 0.478 \\
\hline
\end{tabular}

thermally imidized as fixed on a glass substrate at established temperatures in vacuum and successively annealed without substrates at higher temperatures than the imidization temperatures to remove the residual stress in the films. The detailed conditions for film preparation are shown in Table IV. The obtained PI films (typically $20 \mu \mathrm{m}$ thick) were all high-quality and completely clear. Except for 2,3,6,7-NTDA/ PDA, 2,3,6,7-NTDA/APAB, and PMDA/PDA systems, no cracks were observed in PI films on a $180^{\circ}$ folding test, showing good flexibility.

Complete thermal transformation from PAA to PI was confirmed from the disappearance of amide $\mathrm{C}=\mathrm{O}\left(1657\right.$, and $\left.1556 \mathrm{~cm}^{-1}\right)$ and hydrogen bonded $\mathrm{OH}$ (in $\mathrm{COOH}$, around $2600 \mathrm{~cm}^{-1}$ ) stretching bands and the appearance of the imide carbonyl specific bands $\left(1781,1725,1367,721 \mathrm{~cm}^{-1}\right)$.

\section{Measurements}

The reduced viscosities $\left(\eta_{\text {red }}\right)$ of PAAs were measured at $0.5 \mathrm{wt} \%$ in DMAc at $30^{\circ} \mathrm{C}$ using an Ostwald viscometer. The values of $\eta_{\text {red }}$ obtained so can be regarded as practically inherent viscosities $([\eta])$ since a polyelectrolyte effect causes a significant increase in the $\eta_{\text {red }}$ values at lower PAA concentrations.

The CTEs of the PI specimens $(10 \mathrm{~mm}$ long, $5 \mathrm{~mm}$ wide, and typically $20 \mu \mathrm{m}$ thick) were measured at a heating rate of $5^{\circ} \mathrm{C} \mathrm{min}^{-1}$ as an average within 100 $200^{\circ} \mathrm{C}$ for the film plane direction on a thermomechanical analyzer (Bruker-AXS, TMA 4010) with a load $(0.5 \mathrm{~g}$ per film thickness in $\mu \mathrm{m})$ in a nitrogen flow. In this case, the data were collected from the second heating run after the first run up to $120^{\circ} \mathrm{C}$ to eliminate the adsorbed water since the first run occasionally shows an abnormal TMA curve. Storage modulus $\left(E^{\prime}\right)$ and loss energy $\left(E^{\prime \prime}\right)$ were measured as a function of temperature to determine $T_{\mathrm{g}}$ from a peak temperature of the $E^{\prime \prime}$ curve using the same instrument at a heating rate of $5^{\circ} \mathrm{C} \mathrm{min}-1$ with a sinusoidal load frequency of $0.1 \mathrm{~Hz}$ in a nitrogen atmosphere.

Thermogravimetric analysis (TGA) was conducted to evaluate the thermal stability of the PI films at a heating rate of $10^{\circ} \mathrm{C} \mathrm{min}^{-1}$ in nitrogen and air. The $5 \%$ weight loss temperatures $\left({T_{\mathrm{d}}}^{5}\right)$ were compared.

The in-plane $\left(n_{\text {in }}\right)$ and out-of-plane $\left(n_{\text {out }}\right)$ refractive indices of the PI films were measured at D-line $(589 \mathrm{~nm})$ on an Abbe refractometer (Atago 4T) equipped with a polarizer using a contact liquid (sulfursaturated methylene iodide $n_{\mathrm{D}}=1.78-1.80$ ) and a test piece $\left(n_{\mathrm{D}}=1.92\right)$. The average refractive index was calculated from the relation: $n_{\mathrm{av}}=\left(2 n_{\text {in }}+n_{\text {out }}\right) / 3$. Dielectric constants were estimated from an empirical relation: $\varepsilon_{\text {cal }}=1.1 n_{\mathrm{av}}{ }^{2}$

Ultraviolet-visible transmission spectra of PI films ( $c a .20 \mu \mathrm{m}$ thick) were recorded to evaluate

Table IV. Conditions of 2,3,6,7-NTDA-derived PI film preparation

\begin{tabular}{|c|c|c|c|}
\hline Diamine & $\begin{array}{l}\text { Imidization condition } \\
\text { on substrate }\end{array}$ & $\begin{array}{l}\text { Annealing condition } \\
\text { off substrate }\end{array}$ & $\begin{array}{l}180^{\circ} \text { folding } \\
\text { test }\end{array}$ \\
\hline PDA & $200^{\circ} \mathrm{C} / 1 \mathrm{~h}+330^{\circ} \mathrm{C} / 1 \mathrm{~h}$ & $400^{\circ} \mathrm{C} / 1 \mathrm{~h}$ & $x$ \\
\hline APAB & $300^{\circ} \mathrm{C} / 2 \mathrm{~h}$ & $350{ }^{\circ} \mathrm{C} / 1 \mathrm{~h}$ & $x$ \\
\hline TFMB & $200^{\circ} \mathrm{C} / 1 \mathrm{~h}+330^{\circ} \mathrm{C} / 1 \mathrm{~h}$ & $\begin{array}{l}350^{\circ} \mathrm{C} / 1 \mathrm{~h} \\
\left(400^{\circ} \mathrm{C} / 1 \mathrm{~h}\right)\end{array}$ & O \\
\hline $4,4^{\prime}-\mathrm{ODA}$ & $200^{\circ} \mathrm{C} / 1 \mathrm{~h}+330^{\circ} \mathrm{C} / 1 \mathrm{~h}$ & $\begin{array}{c}350^{\circ} \mathrm{C} / 1 \mathrm{~h} \\
\left(400^{\circ} \mathrm{C} / 1 \mathrm{~h}\right)\end{array}$ & 0 \\
\hline $3,4^{\prime}-\mathrm{ODA}$ & $200^{\circ} \mathrm{C} / 1 \mathrm{~h}+330^{\circ} \mathrm{C} / 1 \mathrm{~h}$ & $400^{\circ} \mathrm{C} / 1 \mathrm{~h}$ & 0 \\
\hline MBCHA (c/t mix) & $200^{\circ} \mathrm{C} / 1 \mathrm{~h}+300^{\circ} \mathrm{C} / 1 \mathrm{~h}$ & $\begin{array}{c}310^{\circ} \mathrm{C} / 1 \mathrm{~h} \\
\left(350^{\circ} \mathrm{C} / 1 \mathrm{~h}\right)\end{array}$ & $\bigcirc$ \\
\hline $\mathrm{t}, \mathrm{t}-\mathrm{MBCHA}$ & $300^{\circ} \mathrm{C} / 2 \mathrm{~h}$ & $350^{\circ} \mathrm{C} / 1 \mathrm{~h}$ & 0 \\
\hline $\operatorname{MBMCHA}(\mathrm{c} / \mathrm{t}$ mix) & $300^{\circ} \mathrm{C} / 1 \mathrm{~h}$ & $320^{\circ} \mathrm{C} / 1 \mathrm{~h}$ & 0 \\
\hline IPDA (c/t mix) & $200^{\circ} \mathrm{C} / 1 \mathrm{~h}+300^{\circ} \mathrm{C} / 1 \mathrm{~h}$ & - & - \\
\hline NBDA & $\begin{array}{c}350^{\circ} \mathrm{C} / 2 \mathrm{~h} \\
\left(300^{\circ} \mathrm{C} / 2 \mathrm{~h}\right)\end{array}$ & $350^{\circ} \mathrm{C} / 1 \mathrm{~h}$ & O \\
\hline
\end{tabular}


the film transparency on a Jasco UV-VIS V-530 spectrometer.

Water absorption $\left(\mathrm{W}_{\mathrm{A}}\right)$ was determined from the relation: $\left(\mathrm{W}-\mathrm{W}_{0}\right) / \mathrm{W}_{0} \times 100(\%)$, where $\mathrm{W}_{0}$ is the weight of PI films after immediately vacuum-drying at $50^{\circ} \mathrm{C}$ for $24 \mathrm{~h}, \mathrm{~W}$ denotes the weight of PI films which were immersed in water at $25^{\circ} \mathrm{C}$ for $24 \mathrm{~h}$ and wiped with a tissue paper.

Tensile modulus, strength, and elongation at break $\left(\mathrm{E}_{\mathrm{b}}\right)$ of the PI specimens ( $3 \mathrm{~mm}$ wide and $30 \mathrm{~mm}$ long) were measured using a mechanical testing machine (Toyo Boldwin, Tensilon UTM-II) at a cross head speed of $8 \mathrm{~mm} \mathrm{~min}^{-1}$.

\section{RESULTS AND DISCUSSION}

\section{Polymerizability of 2,3,6,7-NTDA with Various Di- amines}

Polymerizability of 2,3,6,7-NTDA with aromatic and cycloaliphatic diamines was evaluated on the basis of the final inherent viscosities of the resultant PAAs. In this paper, we use the term 'polymerizability' as a criterion representing how the polymerization of PAAs proceed smoothly, as a result, afford higher molecular weight (higher $[\eta]$ ) PAAs. Therefore, polymerizability is supposed to be influenced by total effects of chemical and physical parameters: intrinsic monomer reactivity, the solubility of the monomers and the polymers (oligomers or intermediates) formed, since precipitation inhibits the progress of polymerization. Thus, the use of monomers possessing higher intrinsic reactivity does not always give higher molecular weight PAAs. The systems using aliphatic diamines are the case as discussed later. In the systems using aromatic diamines, higher intrinsic reactivity of monomers usually leads to higher molecular weight PAAs.

Table II summarizes the polymerization conditions and the inherent viscosities of the PAAs obtained. First, one of the most reactive aromatic diamine, flexible ether-containing 4,4'-ODA was used. In many cases, PAAs possessing $[\eta]>1 \mathrm{dL} \mathrm{g}^{-1}$ as an empirical criterion lead to tough PI films. Film toughness is also a very important factor for FCCL application. In the 2,3,6,7-NTDA/4,4'-ODA system, the polymerization proceeded very smoothly as in familiar PMDA/4,4'-ODA system and led to a considerably high inherent viscosity of PAA $([\eta]=6.35 \mathrm{dL} / \mathrm{g})$, indicating excellent reactivity of 2,3,6,7-NTDA.

Diamines possessing stiff/linear structures such as PDA, APAB, TFMB, and CHDA were also used since these are expected to give PI films showing low CTE values which are one of the present targets. These "rigid" systems also led to considerably high inherent viscosities; $[\eta]=5.80 \mathrm{dL} \mathrm{g}^{-1}$ for the PDA system,
$2.21 \mathrm{dL} \mathrm{g}^{-1}$ for APAB system. Even TFMB, which has lower reactivity than common aromatic diamines such as $4,4^{\prime}$-ODA owing to the presence of electronwithdrawing trifluoromethyl groups, provided a high inherent viscosity of $2.15 \mathrm{dL} \mathrm{g}^{-1}$.

Our previous studies revealed that CHDA also behaves as a stiff structural unit, as well as PDA. ${ }^{17,21}$ In addition, the use of non-aromatic diamines such as CHDA also inhibits both intra- and intermolecular charge-transfer (CT) interactions. ${ }^{22}$ Then we tried to polymerize the PAA of 2,3,6,7-NTDA/CHDA system with an expectation that this system should give a low-CTE and colorless PI film. However, the polymerization of the CHDA-based PAA was completely inhibited both in NMP and DMAc even after prolonged stirring at room temperature. This is most likely attributed to practically insoluble salt formed between unreacted free $\mathrm{NH}_{2}$ and $\mathrm{COOH}$ groups in the initially formed low molecular weight amic acids with a crosslinked structure as observed in the PMDA/CHDA system (PMDA = pyromellitic dianhydride). ${ }^{23}$ Then the in-situ silylation technique ${ }^{24}$ was applied to the present system to avoid the salt formation. However, unfortunately, this attempt did not improve its poor polymerizability; the reaction mixture remained inhomogeneous even after prolonged stirring at room temperature, probably owing to precipitation of the partially formed silylated PAA. A similar result was observed in the PMDA/CHDA system although its polymerization was allowed only in hexamethylphosphoramide (HMPA) or a HMPAcontaining mixed solvent. In the present work, we did not conduct the polymerization runs of the 2,3,6,7-NTDA/CHDA system in toxic HMPA.

It is of interest that the use of MBCHA (cis/trans mixture) possessing a flexible methylene linkage, instead of CHDA, allowed to readily polymerize in DMAc owing to gradual dissolution of the salt and gave a viscous/homogeneous PAA solution. This dramatic change in the PAA polymerizability probably results from a slightly increased salt solubility arising from a decrease in ionic crosslinking density due to the presence of a flexible methylene spacer in MBCHA, thereby the solvent molecules can penetrate into the salt inside. Other cycloaliphatic diamines with flexible linkages ( $\mathrm{t} / \mathrm{t}-\mathrm{MBCHA}$, MBMCHA, IPDA, NBDA) also showed good polymerizability as illustrated from high inherent viscosities ranging 0.64$2.00 \mathrm{dL} \mathrm{g}^{-1}$ (see Table II). Then we attempted to incorporate CHDA partially by copolymerization with MBCHA. At a composition of CHDA $=40 \mathrm{~mol} \%$, the copolymerization was allowed although the reaction mixture consisting of CHDA $=50 \mathrm{~mol} \%$ remained inhomogeneous even after prolonged stirring. The 2,3,6,7-NTDA-based PAA cast films obtained 
were all flexible and passed through the $180^{\circ}$ folding test, corresponding to their sufficiently high inherent viscosities.

\section{Comparison of Polymerizability with 1,4,5,8-NTDA Systems}

The polymerizability of 2,3,6,7-NTDA was compared with that of its isomer, 1,4,5,8-NTDA. Table III lists the conditions and results of polymerization. In spite of the use of intrinsically highly reactive $4,4^{\prime}$-ODA, the polymerization did not smoothly proceed: after the dianhydride powder was all added, the reaction mixture temporary turned to a poorly viscous red clear solution after several hours, but it soon became turbid owing to some precipitation. The precipitate probably consists of an amic acid oligomer possessing poor solubility in NMP. But, the precipitate could be dissolved upon mild heating around $80^{\circ} \mathrm{C}$ to form a clear solution. The inherent viscosity of PAA(1,4,5,8-NTDA/4,4'-ODA) was $0.284 \mathrm{dL} \mathrm{g}^{-1}$, showing poor polymerizability. The homogeneous PAA solution was cast at $80^{\circ} \mathrm{C}$ for $1 \mathrm{~h}$ on a glass plate, however, many cracks formed in the cast film inhibited film preparation. The poor polymerizability in the $1,4,5,8$-NTDA $/ 4,4^{\prime}$-ODA system is probably attributed to intrinsically low reactivity toward the ring-opening amide formation for the anhydride groups in 1,4,5,8-NTDA rather than its limited solubility in DMAc and NMP commonly used for PAA polymerization, since s-BPDA, which is practically insoluble in these solvents, easily leads to high molecular weight PAAs by the reaction with most of diamines. The predicted poor reactivity of $1,4,5,8$ NTDA arises from the thermodynamically more stable six-membered structure of the dicarboxylic anhydride groups in contrast to five-membered structure of 2,3,6,7-counterpart. A similar situation was observed in 3,4,9,10-perylenetetracarboxylic dianhydride bearing six-membered anhydride rings, which was allowed to react with amines to synthesize a low molecular weight compound only under a special condition in the presence of a catalyst. ${ }^{13}$ The difficulty of PAA polymerization for 1,4,5,8-NTDA may correspond to suppressed acid-catalyzed hydrolysis for 1,4,5,8-NTDA-derived polyimides used as protonconductive membranes in high temperature fuel cell systems. ${ }^{19}$

Even the use of cycloaliphatic diamines possessing much higher basicity than aromatic diamines was less effective for the PAA homopolymerization using only $1,4,5,8-N T D A$ as a dianhydride component. However, it was possible to copolymerize with 6FDA when a minor portion of $1,4,5,8-\mathrm{NTDA}(\leq 30 \mathrm{~mol} \%)$ was used as shown in Table III. Because of its poor PAA polymerizability under the common conditions,
1,4,5,8-NTDA-based polyimides are usually prepared by the one-pot polymerization technique, ${ }^{19}$ which is conducted at elevated temperatures in the presence of bases such as picoline as a catalyst for imidization and toluene or xylene to azeotropically remove water coming from imidization. ${ }^{25}$ However, even if a homogeneous solution consisting of a 1,4,5,8-NTDA-based PI soluble in common organic solvents is available via the one-pot technique, it is not applicable to the present purpose since the in-plane orientation of PI chains as a primary factor for low CTE characteristics can be induced by thermal imidization of PAA films. ${ }^{13}$ Thus, the difficulty of PAA polymerization using 1,4,5,8NTDA prevents the applications to adhesive-free (two-layered) FCCL, again emphasizing considerably high polymerizability of 2,3,6,7-NTDA.

\section{Imidization-Induced In-Plane Orientation Relating to PI Chain Structures}

In the present work, CTE is one of the most interested properties for us. The CTE of PI films is controlled by a very complicated mechanism. In s-BPDA/ PDA $^{13}$ and PMDA $/ 4,4^{\prime}$-ODA systems, ${ }^{12}$ a good correlation was observed between CTE and the extent of in-plane orientation $\left(\mathrm{f}_{\mathrm{IP}}\right)$ or $\Delta n\left(n_{\text {in }}-n_{\text {out }}\right)$, which represents how the polymer segments align parallel to the film plane: In fact, CTE decreased almost linearly with increasing $f_{I P}$. The in-plane orientation is poor in PAA cast films independent of their chemical structures, however, it is significantly intensified during thermal imidization in some systems. We have previously investigated the factors influencing the imidization-induced in-plane chain orientation responsible for low CTE characteristics by monitoring the dichroic ratios measured at a tilt angle for the dye-labeled PAA and PI films. ${ }^{13}$ The results revealed that the linearity/stiffness of PI backbone structures is one of the primary factors. A typical rod-like structure of PI is PMDA/PDA system (Figure 2), of which the linear chain form is almost maintained even after conformational changes. Accordingly, $p$-biphenylene and $p$ terphenylene linkages are classified into the stiff/ linear structural units favorable for in-plane orientation. Thus, s-BPDA/PDA and TPDA/PDA containing these stiff units are also known as low-CTE PIs in contrast to sterically distorted 2,3,3', $4^{\prime}$-BPDA (aBPDA)-derived PIs. ${ }^{25-27}$ Figure 2 illustrates the backbone structures of typical low-CTE polyimide systems.

Recently we have shown that $p$-aromatic ester linkages also behave as stiff/linear structural units. For example, TAHQ- and APAB-based poly(ester imide)s are the case. ${ }^{18}$ Why do the stiff/linear chain structures cause significant in-plane orientation? Although it is far from being fully understood, a possible interpreta- 
(a)

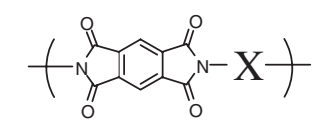

(b)

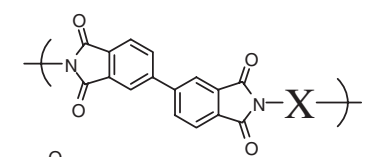

(c)

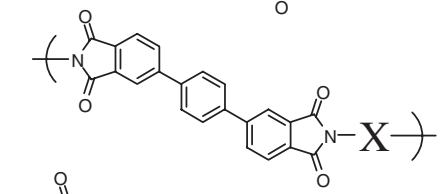

(d)

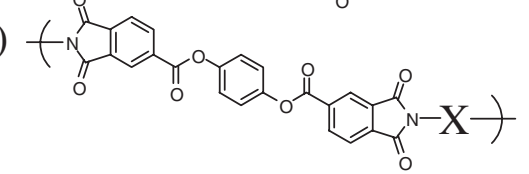

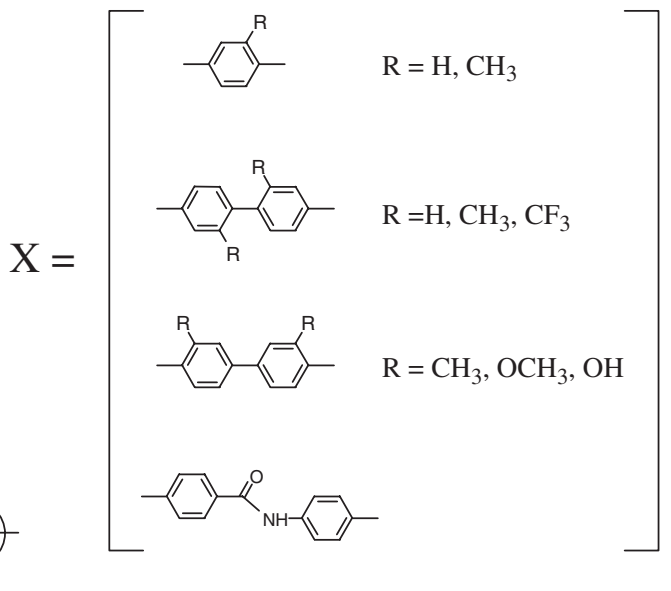

Figure 2. Typical chain backbones of low-CTE polyimides derived from stiff/linear structures of tetracarboxylic dianhydrides and diamines: (a) PMDA, (b) s-BPDA, (c) TPDA, and (d) TAHQ systems.

tion is that liquid crystal-like ordered structure can act as a trigger of the spontaneous in-plane orientation. This idea comes from the fact that thermal imidization of a lyotropic liquid crystalline partially imidized PAA(s-BPDA/PDA) film caused a lower CTE than that of the corresponding amorphous PAA. ${ }^{28}$ Other supportive information for our hypothesis is that a liquid crystal phase was observed in a low molecular weight 3,3',4,4'-biphenyldiimide compound possessing long alkyl chains ${ }^{29}$ on a polarizing optical microscope equipped with a hot stage as in an TAHQ-analogue used in our preliminary experiments.

On the basis of the hypothesis mentioned above, it is expected that the introduction of bulky substituents into the main chains should disturb liquid crystal-like intermolecular interactions. In fact, a PI derived from s-BPDA and 2,5-dimethyl-substituted PDA (DMPDA), despite that it has the same backbone structure as a typical low-CTE polyimide, s-BPDA/ PDA, exhibited no in-plane orientation during thermal imidization. No local ordering was also observed in the s-BPDA/DMPDA PI film, corresponding to the fact that its PI film remained being poor molecular packing as estimated from a very low film density, whereas non-substituted s-BPDA/PDA showed a significant increase in film density with increasing imidization (or annealing) temperature in accordance with pronounced structure-organization (crystallization). ${ }^{26,30}$ From these results, we came up to an empirical criterion that the introduction of too many bulky substituents (more than two) on an aromatic ring should be avoided to obtain low-CTE PIs. A stiff/ linear structure of non-substituted 2,3,6,7-NTDA is expected as a novel tetracarboxylic dianhydride monomer which can contribute to low CTE generation, when 'rigid' diamines such as PDA, TFMB, $\mathrm{APAB}$, and CHDA were used.
Film Properties of 2,3,6,7-NTDA-Derived Polyimides

The PI films were prepared under the conditions listed in Table IV. The $180^{\circ}$ folding test suggested that all the PI films were qualitatively flexible except for the 2,3,6,7-NTDA/PDA and 2,3,6,7-NTDA/ APAB systems. The brittleness of the 2,3,6,7NTDA/PDA film is attributed to poor chain entanglement arising from its rod-like structure as shown in a similar structure of PMDA/PDA polyimide film.

Table V summarizes the film properties of 2,3,6,7NTDA-derived PIs. In the 2,3,6,7-NTDA/PDA system, no distinct glass transition was detected up to $500^{\circ} \mathrm{C}$ in the DMTA curves as in the $2,3,6,7$ NTDA/APAB system. A typical DMTA curve is shown in Figure 3a. The result is based on the suppressed molecular motion (internal rotation) in the amorphous regions even above the $T_{\mathrm{g}}$ or may be due to a glass transition present in a higher temperature region than thermal decomposition temperatures $\left(>500^{\circ} \mathrm{C}\right)$. A sign of glass transition was barely detected around $420^{\circ} \mathrm{C}$ for $2,3,6,7-\mathrm{NTDA} / \mathrm{TFMB}$ polyimide film, reflecting poor molecular mobility even above the $T_{\mathrm{g}}$ (in other words, excellent dimensional stability).

According to our first expectation, 2,3,6,7-NTDAbased PI systems consisting of rigid diamines gave low CTE values. It should be noted that the 2,3,6,7NTDA/PDA film exhibited an extremely low CTE (3.0 ppm K ${ }^{-1}$ ) comparable to that of a silicon wafer, reflecting its considerably high birefringence $(\Delta n=$ 0.196). Empirically speaking, $\Delta n \geq 0.1$ represents a criterion where aromatic PI chains are highly aligned parallel to the film plane. The 2,3,6,7-NTDA/APAB system also showed similar super-low CTE characteristics.

Although negative CTEs are often observed in highly uniaxially stretched samples (typically fibers) 
Table V. Properties of 2,3,6,7-NTDA-based PI films

\begin{tabular}{|c|c|c|c|c|c|c|c|c|c|c|c|}
\hline Diamines & $\begin{array}{c}T_{\mathrm{g}} \\
\left({ }^{\circ} \mathrm{C}\right)\end{array}$ & $\begin{array}{c}\text { CTE } \\
(\mathrm{ppm} / \mathrm{K})\end{array}$ & $\Delta n$ & $\varepsilon_{\mathrm{cal}}$ & $\begin{array}{l}\mathrm{W}_{\mathrm{A}} \\
(\%)\end{array}$ & $\begin{array}{l}\text { Modulus } \\
\text { (GPa) }\end{array}$ & $\begin{array}{l}\mathrm{E}_{\mathrm{b}} \\
(\%)\end{array}$ & $\begin{array}{c}\text { Cut } \\
\text { off } \\
(\mathrm{nm})\end{array}$ & $\begin{array}{c}\mathrm{T} \% \\
(400 \mathrm{~nm})\end{array}$ & $\begin{array}{c}T_{\mathrm{d}}^{5} \text { in } \\
\mathrm{N}_{2} \\
\left({ }^{\circ} \mathrm{C}\right)\end{array}$ & $\begin{array}{c}T_{\mathrm{d}}^{5} \\
\text { in air } \\
\left({ }^{\circ} \mathrm{C}\right)\end{array}$ \\
\hline PDA & $\mathrm{ND}^{\mathrm{a})}$ & 3.1 & 0.196 & 3.27 & - & - & - & 439 & 0 & $>590^{\mathrm{c})}$ & 580 \\
\hline APAB & $\mathrm{ND}^{\mathrm{a})}$ & 3.0 & 0.179 & 3.28 & 1.22 & - & - & 405 & 0 & 556 & 553 \\
\hline TFMB & 420 & -3.2 & 0.203 & 3.09 & 0.36 & 7.53 & 19.0 & 390 & 28.0 & 582 & 559 \\
\hline $4,4^{\prime}-\mathrm{ODA}$ & 408 & 20.0 & $>0.119^{b)}$ & $>3.38$ & 1.16 & 2.10 & 87.2 & 428 & 0 & 580 & 570 \\
\hline $3,4^{\prime}-\mathrm{ODA}$ & 403 & 30.5 & $>0.115^{\mathrm{b})}$ & $>3.37$ & 1.00 & 3.16 & 50.4 & 415 & 0 & 582 & 568 \\
\hline MBCHA (c/t mix) & 376 & 45.2 & 0.034 & 2.96 & 0.97 & 2.15 & 20.7 & 385 & 73.3 & 465 & 403 \\
\hline $\mathrm{t}, \mathrm{t}-\mathrm{MBCHA}$ & 394 & 46.2 & 0.037 & 2.98 & - & - & - & 385 & 75.4 & 465 & 405 \\
\hline MBMCHA (c/t mix) & 347 & 51.0 & 0.016 & 2.88 & 1.57 & 2.22 & 14.0 & 384 & 72.9 & 448 & 381 \\
\hline NBDA & 372 & 46.3 & 0.015 & 3.03 & - & - & - & 385 & 74.0 & 488 & 425 \\
\hline
\end{tabular}

a) $\mathrm{ND}=$ not detected up to $450^{\circ} \mathrm{C}$ in dynamic mechanical thermal analysis (DMTA). b) $\mathrm{n}_{\text {in }}$ exceeded an experimental upper limit $\left(n_{\mathrm{D}}=1.78-1.80\right.$ for sulfur-saturated methylene iodide as a contact liquid in refractive index measurements). c) $5 \%$ weight loss temperature is estimated to be more than an experimental upper limit temperature of the heating run $\left(590^{\circ} \mathrm{C}\right)$, for the use of aluminum pans in TGA.
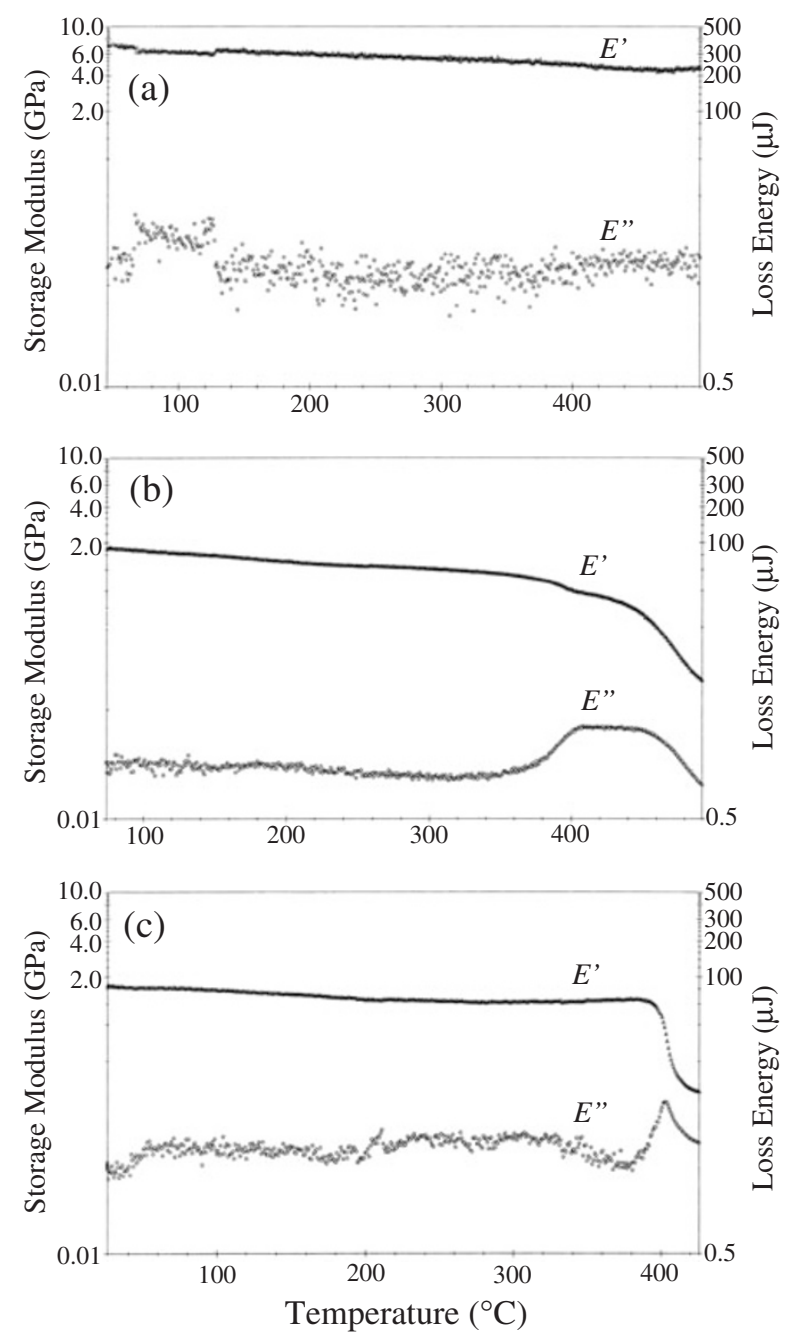

Figure 3. DMTA curves of PI films: (a) 2,3,6,7-NTDA/PDA, (b) 2,3,6,7-NTDA/4,4'-ODA, and (c) 2,3,6,7-NTDA/3,4'-ODA.

along the stretching direction, ${ }^{31}$ it is very curious that 2,3,6,7-NTDA/TFMB film displayed a negative CTE $\left(-3.2 \mathrm{ppm} \mathrm{K}^{-1}\right)$ despite that the film was non-stretch- ed. This unusual behavior is also observed in some limited systems, PMDA/TFMB and PMDA $/ m$-tolidine ( $m$-TOL). We have previously proposed a mechanism for the negative CTE. ${ }^{28,32}$ The volumetric coefficient of thermal expansion $(\beta)$ is expressed as:

$$
\beta=\alpha_{\mathrm{x}}+\alpha_{\mathrm{y}}+\alpha_{\mathrm{z}}=2 \alpha_{\mathrm{in}}+\alpha_{\mathrm{z}}
$$

where $\alpha_{\mathrm{x}}, \alpha_{\mathrm{y}}$, and $\alpha_{\mathrm{z}}$ represent the linear coefficient of thermal expansion in the in-plane ( $\mathrm{x}$ and $\mathrm{y}$ ) and outof-plane (z) directions, respectively. For non-stretched films (the present case), $\alpha_{\mathrm{x}}$ is equivalent to $\alpha_{\mathrm{y}}$, then $\alpha_{\mathrm{x}}+\alpha_{\mathrm{y}}=2 \alpha_{\text {in }}$ where $\alpha_{\text {in }}$ denotes $\alpha$ in the in-plane direction, that is, the measured CTE in the present work.

In general, $\beta$ is intrinsic to the system and independent of both the modes and the extent of orientation unless crystallinity changed significantly. Therefore, if a film specimen showed a considerably high thermal expansion toward the out-of plane (thickness) direction (very large $\alpha_{\mathrm{z}}$ ), the film can contract toward the film plane direction (negative $\alpha_{\text {in }}$ ) to maintain $\beta$ at a constant value. When the highly in-plane oriented film possesses a less crystalline morphology, the film may be allowed to thermally expand significantly toward the thickness direction. A common structural feature in these negative-CTE PI systems is the presence of bulky substituents in the structures $\left(\mathrm{CF}_{3}\right.$ and $\mathrm{CH}_{3}$ groups) which can contribute to disturb crystallization.

The 2,3,6,7-NTDA/TFMB film also displayed excellent combined properties: low water absorption $\left(\mathrm{W}_{\mathrm{A}}=0.36 \%\right)$, high tensile modulus $(7.53 \mathrm{GPa})$ and strength $(0.262 \mathrm{GPa})$, and sufficient film toughness $\left(\mathrm{E}_{\mathrm{b}}=19 \%\right)$ in addition to good thermal stability (5\% weight loss temperature $T_{\mathrm{d}}{ }^{5}=582^{\circ} \mathrm{C}$ in $\mathrm{N}_{2}$ and $559^{\circ} \mathrm{C}$ in an air atmosphere). Another feature of this fluorinated PI film is relatively good transparency in the ultraviolet-visible range. The film is slightly 
Table VI. Properties of PI films consisting of PDA and different dianhydrides.

The data of the 2,3,6,7-NTDA system were extracted from Table $\mathrm{V}$ for a comparison

\begin{tabular}{cccccccccccc}
\hline Diamines & $\begin{array}{c}T_{\mathrm{g}} \\
\left({ }^{\circ} \mathrm{C}\right)\end{array}$ & $\begin{array}{c}\mathrm{CTE} \\
(\mathrm{ppm} / \mathrm{K})\end{array}$ & $\Delta n$ & $\varepsilon_{\mathrm{cal}}$ & $\begin{array}{c}\mathrm{W}_{\mathrm{A}} \\
(\%)\end{array}$ & $\begin{array}{c}\text { Modulus } \\
(\mathrm{GPa})\end{array}$ & $\begin{array}{c}\mathrm{E}_{\mathrm{b}} \\
(\%)\end{array}$ & $\begin{array}{c}\mathrm{Cut} \\
\text { off } \\
(\mathrm{nm})\end{array}$ & $\begin{array}{c}\mathrm{T} \% \\
(400 \mathrm{~nm})\end{array}$ & $\begin{array}{c}T_{\mathrm{d}}^{5} \text { in } \mathrm{N}_{2} \\
\left({ }^{\circ} \mathrm{C}\right)\end{array}$ & $\begin{array}{c}T_{\mathrm{d}}^{5} \\
\text { in air } \\
\left({ }^{\circ} \mathrm{C}\right)\end{array}$ \\
\hline PMDA $^{\mathrm{a})}$ & $\mathrm{ND}^{\mathrm{c})}$ & 3.2 & 0.182 & 3.21 & - & - & - & 447 & 0 & 576 & 551 \\
s-BPDA $^{\mathrm{b})}$ & $370^{\mathrm{d})}$ & 10.3 & 0.224 & 3.46 & 1.15 & 7.97 & 34.5 & 414 & 0 & 587 & 571 \\
$2,3,6,7-\mathrm{NTDA}^{2}$ & $\mathrm{ND}$ & 3.1 & 0.196 & 3.27 & - & - & - & 439 & 0 & $>590^{\mathrm{e})}$ & 580 \\
\hline
\end{tabular}

a) imidized at $400{ }^{\circ} \mathrm{C} / 1 \mathrm{~h}$ in vacuum on a substrate, then annealed at $405^{\circ} \mathrm{C} / 1 \mathrm{~h}$ in vacuum without substrate. b) imidized at $200^{\circ} \mathrm{C} /$ $1 \mathrm{~h}+300^{\circ} \mathrm{C} / 1 \mathrm{~h}$ in vacuum on a substrate, then annealed at $400^{\circ} \mathrm{C} / 1 \mathrm{~h}$ in vacuum without substrate. c) not detected up to $500^{\circ} \mathrm{C}$ in DMTA. d) ref. 27. e) $5 \%$ weight loss temperature is estimated to be more than an experimental upper limit temperature of the heating run $\left(590^{\circ} \mathrm{C}\right)$, coming from the melting point of aluminum pan used in TGA.

colored but possessed much higher transparency (transmittance $\mathrm{T}=28 \%$ at $400 \mathrm{~nm}$ ) than the 2,3,6,7NTDA/PDA and 2,3,6,7-NTDA/APAB films $(\mathrm{T}=$ $0 \%)$. This can be reasonably assumed to be due to partially inhibited intra- and intermolecular charge-transfer (CT) interactions ${ }^{22}$ by the presence of electronwithdrawing and bulky $\mathrm{CF}_{3}$ groups on the TFMB moiety which prevent dense interchain stacking.

The film properties of 2,3,6,7-NTDA PI system derived from a representative flexible diamine, 4, $4^{\prime}$ ODA, are also evaluated in this work. This PI film exhibited an extremely high $T_{\mathrm{g}}$ exceeding $400^{\circ} \mathrm{C}$, in spite of the presence of flexible ether linkages. Figure $3 b$ shows its DMTA curve. A poor thermoplasticity was observed above the $T_{\mathrm{g}}$. This wholly aromatic PI system provided a highly tough film as indicated from its considerably high $\mathrm{E}_{\mathrm{b}}$ value $(>80 \%)$ due to good chain entanglement in addition to high thermal stability, corresponding to our expectation. Another notable feature of the $2,3,6,7-\mathrm{NTDA} / 4,4^{\prime}$-ODA system is that it is to show a low CTE value (20.0 ppm K $\mathrm{K}^{-1}$ ) close to that of copper substrates and relatively low water absorption (1.16\%). The results suggest that the excellent combined properties can be applied to novel high temperature substrates for FCCL. The 2,3,6,7-NTDA/3,4'-ODA film also showed excellent combined properties comparable to the $4,4^{\prime}$ ODA system with an exception of the DMTA curves. Figure $3 \mathrm{c}$ shows the DMTA curves of the 2,3,6,7NTDA $/ 3,4^{\prime}$-ODA film. A certain degree of thermoplasticity was observed above the $T_{\mathrm{g}}$, as shown in common cases where meta-linked or asymmetrically linked aromatic diamines were used.

As stated above, when aliphatic diamines were used instead of aromatic diamines, the PI film transparency can be dramatically improved by the inhibited CT interactions. Indeed, the transmittance (T\%) at $400 \mathrm{~nm}$ significantly increased from $0 \%$ for the $4,4^{\prime}$-ODA system to more than $70 \%$ for MBCHAmix, t,t-MBCHA, MBMCHA, and NBDA systems. It should be noted that these semi-cycloaliphatic PIs possessed very high
$T_{\mathrm{g}}$ values in the range of $347-394{ }^{\circ} \mathrm{C} . T_{\mathrm{g}}$ was positioned at $372{ }^{\circ} \mathrm{C}$ even when NBDA containing two flexible methylene linkages was used. This can be interpreted in terms of the restricted internal rotation originating from the large naphthaldiimide molecular plane and strong intermolecular forces between the highly polarized imide carbonyl groups. Although the decrease in thermal stability compared with the wholly aromatic 2,3,6,7-NTDA-based PIs is inevitable owing to the presence of thermally less stable aliphatic moieties, the values of $T_{\mathrm{d}}{ }^{5}$ still remain sufficiently high.

\section{Comparisons with Other PI Systems from Different Dianhydrides}

In order to elucidate some merits of the 2,3,6,7NTDA-based PI systems, the film properties were compared with those of PIs from different "rigid" dianhydrides and a fixed diamine. PMDA and s-BPDA were chosen as rigid dianhydrides for the comparisons. Table VI lists an effect of dianhydride on the film properties for the PDA-based PIs. The 2,3,6,7NTDA/PDA polyimide film showed equivalent properties to the PMDA/PDA system, namely, an undetected glass transition (in other words, good dimensional stability), an extremely low CTE close to the value of silicon wafer, and high thermal stability. The very poor film toughness observed in these rod-like PI systems, in contrast to s-BPDA/PDA, arises from the unexpected chain entanglement. In comparison between the APAB-based PI systems, Table VII also showed almost no prominent difference of the film properties except for water absorption behavior. The degree of water absorption decreased in the following order: PMDA/APAB (1.60\%) > 2,3,6,7-NTDA/APAB (1.22\%) > s-BPDA/APAB $(0.70 \%)$. This corresponds to the order of the content of highly polarizable imide groups: PMDA/APAB $(34.13 \mathrm{wt} \%)>2,3,6,7-\mathrm{NTDA} / \mathrm{APAB}(30.42 \mathrm{wt} \%)>$ s-BPDA/APAB (28.79 wt \%), which were calculated from the relation: $\mathrm{F}_{\mathrm{w}}$ (imide) $/ \mathrm{F}_{\mathrm{w}}$ (unit) $\times 100(\mathrm{wt} \%)$ 
Low-CTE Polyimides Derived from 2,3,6,7-Naphthalenetetracarboxylic Dianhydride

Table VII. Properties of PI films consisting of APAB and different dianhydrides.

The data of the 2,3,6,7-NTDA system were extracted from Table $\mathrm{V}$ for a comparison

\begin{tabular}{cccccccccccc}
\hline Diamines & $\begin{array}{c}T_{\mathrm{g}} \\
\left({ }^{\circ} \mathrm{C}\right)\end{array}$ & $\begin{array}{c}\mathrm{CTE} \\
(\mathrm{ppm} / \mathrm{K})\end{array}$ & $\Delta n$ & $\varepsilon_{\text {cal }}$ & $\begin{array}{c}\mathrm{W}_{\mathrm{A}} \\
(\%)\end{array}$ & $\begin{array}{c}\text { Modulus } \\
(\mathrm{GPa})\end{array}$ & $\begin{array}{c}\mathrm{E}_{\mathrm{b}} \\
(\%)\end{array}$ & $\begin{array}{c}\text { Cut } \\
\text { off } \\
(\mathrm{nm})\end{array}$ & $\begin{array}{c}\mathrm{T}_{\%} \\
(400 \mathrm{~nm})\end{array}$ & $\begin{array}{c}T_{\mathrm{d}}^{5} \\
\text { in } \mathrm{N}_{2} \\
\left({ }^{\circ} \mathrm{C}\right)\end{array}$ & $\begin{array}{c}T_{\mathrm{d}}^{5} \\
\text { in air } \\
\left({ }^{\circ} \mathrm{C}\right)\end{array}$ \\
\hline PMDA $^{\mathrm{a})}$ & $\mathrm{ND}$ & 2.0 & 0.172 & 3.29 & 1.60 & 7.69 & 6.4 & 347 & 26.1 & 531 & 501 \\
s-BPDA $^{\text {a) }}$ & $\mathrm{ND}$ & 3.4 & 0.183 & 3.28 & 0.70 & 7.59 & 6.0 & 385 & 16.7 & 534 & 525 \\
$2,3,6,7-\mathrm{NTDA}^{2}$ & $\mathrm{ND}$ & 3.0 & $>0.179^{\mathrm{b})}$ & $>3.28$ & 1.22 & - & - & 406 & 0 & 556 & 553 \\
\hline
\end{tabular}

a) imidized at $250^{\circ} \mathrm{C} / 1 \mathrm{~h}+300^{\circ} \mathrm{C} / 1 \mathrm{~h}$ in vacuum on a substrate, then annealed at $350{ }^{\circ} \mathrm{C} / 1 \mathrm{~h}$ in vacuum without substrate. b) $n_{\text {in }}$ exceeded an experimental upper limit $\left(n_{\mathrm{D}}=1.78-1.80\right.$ for sulfur-saturated methylene iodide as a contact liquid in refractive index measurements).

Table VIII. Properties of PI films consisting of TFMB and different dianhydrides.

The data of the 2,3,6,7-NTDA system were extracted from Table V for a comparison

\begin{tabular}{cccccccccccc}
\hline Diamines & $\begin{array}{c}T_{\mathrm{g}} \\
\left({ }^{\circ} \mathrm{C}\right)\end{array}$ & $\begin{array}{c}\mathrm{CTE} \\
(\mathrm{ppm} / \mathrm{K})\end{array}$ & $\Delta n$ & $\varepsilon_{\mathrm{cal}}$ & $\begin{array}{c}\mathrm{W}_{\mathrm{A}} \\
(\%)\end{array}$ & $\begin{array}{c}\text { Modulus } \\
(\mathrm{GPa})\end{array}$ & $\begin{array}{c}\mathrm{E}_{\mathrm{b}} \\
(\%)\end{array}$ & $\begin{array}{c}\text { Cut } \\
\text { off } \\
(\mathrm{nm})\end{array}$ & $\begin{array}{c}\mathrm{T}^{2} \\
(400 \mathrm{~nm})\end{array}$ & $\begin{array}{c}T_{\mathrm{d}}^{5} \\
\text { in N } \\
\left({ }^{\circ} \mathrm{C}\right)\end{array}$ & $\begin{array}{c}T_{\mathrm{d}}^{5} \\
\text { in air } \\
\left({ }^{\circ} \mathrm{C}\right)\end{array}$ \\
\hline PMDA $^{\mathrm{a})}$ & 400 & -4.7 & 0.131 & 2.86 & 0.47 & 5.95 & 19.6 & 403 & 0 & 589 & 515 \\
s-BPDA $^{\mathrm{b})}$ & 314 & 33.8 & 0.040 & 2.93 & 0.28 & 3.67 & 28.3 & 382 & 42.0 & 571 & 550 \\
$2,3,6,7-N T D A$ & 420 & -3.2 & 0.203 & 3.09 & 0.36 & 7.53 & 19.0 & 391 & 28.0 & 582 & 559 \\
\hline
\end{tabular}

a) imidized at $250{ }^{\circ} \mathrm{C} / 1 \mathrm{~h}+330^{\circ} \mathrm{C} / 1 \mathrm{~h}$ in vacuum on a substrate, then annealed at $370{ }^{\circ} \mathrm{C} / 1 \mathrm{~h}$ in vacuum without substrate. b) imidized at $250{ }^{\circ} \mathrm{C} / 1 \mathrm{~h}+300^{\circ} \mathrm{C} / 1 \mathrm{~h}$ in vacuum on a substrate, then annealed at $305^{\circ} \mathrm{C} / 1 \mathrm{~h}$ in vacuum without substrate.

Table IX. Properties of PI films consisting of 4,4'-ODA and different dianhydrides.

The data of the 2,3,6,7-NTDA system were extracted from Table $\mathrm{V}$ for a comparison

\begin{tabular}{cccccccccccc}
\hline Diamines & $\begin{array}{c}T_{\mathrm{g}} \\
\left({ }^{\circ} \mathrm{C}\right)\end{array}$ & $\begin{array}{c}\mathrm{CTE} \\
(\mathrm{ppm} / \mathrm{K})\end{array}$ & $\Delta n$ & $\varepsilon_{\mathrm{cal}}$ & $\begin{array}{c}\mathrm{W}_{\mathrm{A}} \\
(\%)\end{array}$ & $\begin{array}{c}\text { Modulus } \\
(\mathrm{GPa})\end{array}$ & $\begin{array}{c}\mathrm{E}_{\mathrm{b}} \\
(\%)\end{array}$ & $\begin{array}{c}\text { Cut } \\
\text { off } \\
(\mathrm{nm})\end{array}$ & $\begin{array}{c}\mathrm{T} \% \\
(400 \mathrm{~nm})\end{array}$ & $\begin{array}{c}T_{\mathrm{d}}^{5} \\
\text { in } \mathrm{N}_{2} \\
\left({ }^{\circ} \mathrm{C}\right)\end{array}$ & $\begin{array}{c}T_{\mathrm{d}}^{5} \\
\text { in air } \\
\left({ }^{\circ} \mathrm{C}\right)\end{array}$ \\
\hline PMDA $^{\mathrm{a})}$ & 409 & 42.8 & 0.054 & 3.19 & 1.70 & 2.80 & 84.6 & 419 & 0 & 567 & 552 \\
s-BPDA $^{\mathrm{b})}$ & 272 & 46.0 & 0.028 & 3.33 & 1.27 & 3.46 & 72.7 & 414 & 0 & 558 & 541 \\
$2,3,6,7-\mathrm{NTDA}^{2}$ & 408 & 20.0 & $>0.119$ & $>3.37$ & 1.16 & 2.10 & 87.2 & 428 & 0 & 580 & 570 \\
\hline
\end{tabular}

a) imidized at $200^{\circ} \mathrm{C} / 1 \mathrm{~h}+300^{\circ} \mathrm{C} / 1 \mathrm{~h}$ in vacuum on a substrate, then annealed at $400{ }^{\circ} \mathrm{C} / 1 \mathrm{~h}$ in vacuum without substrate. b) imidized at $320^{\circ} \mathrm{C} / 1 \mathrm{~h}$ in vacuum on a substrate, then annealed at $250^{\circ} \mathrm{C} / 1 \mathrm{~h}$ in vacuum without substrate.

where $F_{w}$ (imide) and $F_{w}$ (unit) denote the formula weights of the imide group $(\mathrm{O}=\mathrm{C}-\mathrm{N}-\mathrm{C}=\mathrm{O})$ and the repeating unit. Thus, the imide group content must be a primary factor influencing the water absorption of PI films, although it is likely that other factors such as free volume and moisture permeation properties also contribute somewhat to the water absorption.

Some merits of the 2,3,6,7-NTDA systems become evident in the comparison at a fixed diamine, TFMB. As shown in Table VIII, the 2,3,6,7-NTDA/TFMB film provided superior properties to the s-BPDA counterpart with an exception of water absorption: a much higher $T_{\mathrm{g}}$ at $420^{\circ} \mathrm{C}$ and a much lower CTE $\left(-3.2 \mathrm{ppm} \mathrm{K}^{-1}\right)$. These properties look comparable to those of the PMDA/TFMB system. However, it should be noted that the 2,3,6,7-NTDA system has an advantage of a lower extent of water absorption $(0.36 \%)$ than the PMDA counterpart $(0.47 \%)$. Such suppressed water absorption stems from the presence of the hydrophobic $\mathrm{CF}_{3}$ group in the structures.

In Table IX, a pronounced feature of the 2,3,6,7NTDA polyimide was observed when $4,4^{\prime}$-ODA was used as a fixed diamine component, namely, the lowest CTE $\left(20.0 \mathrm{ppm} \mathrm{K}^{-1}\right)$ and the lowest value of water absorption $(1.16 \%)$ among them while retaining a considerably high $T_{\mathrm{g}}$ at $408^{\circ} \mathrm{C}$ and very high toughness $\left(E_{b}>80 \%\right)$. Thus, the use of 2,3,6,7-NTDA is effective for lowering both CTE and water absorption and enhancing $T_{\mathrm{g}}$. The decreased CTE in the 2,3,6,7NTDA/4,4'-ODA system can be explained in terms of its longer mesogenic units $(20.44 \AA)$ than that in PMDA/4,4'-ODA $(18.01 \AA)$ as depicted in Figure 4. The results correspond to the criterion that more stiff/linear chain structures act more efficiently to trigger the imidization-induced in-plane orientation which probably originates from the combination of liquid-crystal-like interactions and an apparent 


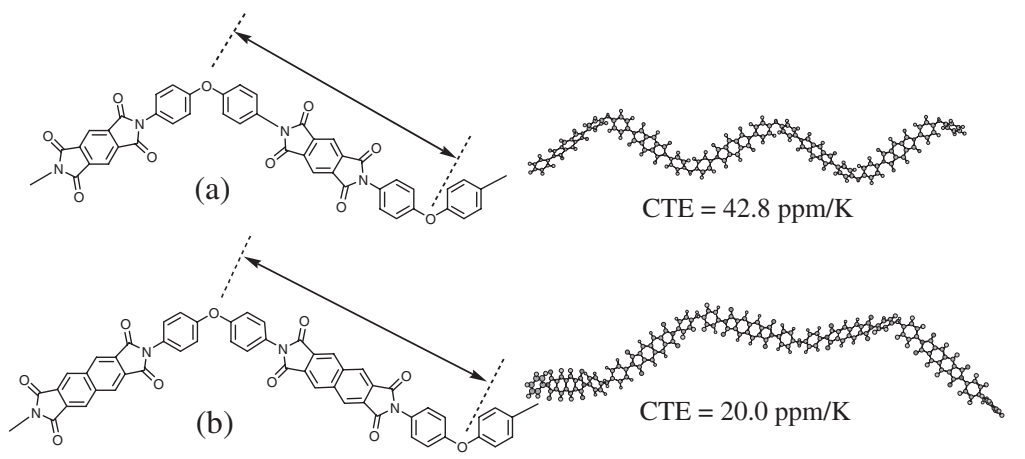

Figure 4. Comparison of mesogenic unit lengths in the extended chains as calculated on a molecular modeling program (Chem Draw 3D, CS-MOPAC and MM2 for oligomeric models of DP = 5): (a) PMDA/4,4'-ODA and (b) 2,3,6,7-NTDA/4,4'-ODA systems.

Table X. Properties of PI films consisting of MBCHA (c/t mix) and different dianhydrides. The data of the 2,3,6,7-NTDA system were extracted from Table $\mathrm{V}$ for a comparison

\begin{tabular}{cccccccccccc}
\hline Diamines & $\begin{array}{c}T_{\mathrm{g}} \\
\left({ }^{\circ} \mathrm{C}\right)\end{array}$ & $\begin{array}{c}\mathrm{CTE} \\
(\mathrm{ppm} / \mathrm{K})\end{array}$ & $\Delta n$ & $\varepsilon_{\text {cal }}$ & $\begin{array}{c}\mathrm{W}_{\mathrm{A}} \\
(\%)\end{array}$ & $\begin{array}{c}\text { Modulus } \\
(\mathrm{GPa})\end{array}$ & $\begin{array}{c}\mathrm{E}_{\mathrm{b}} \\
(\%)\end{array}$ & $\begin{array}{c}\text { Cut } \\
\text { off } \\
(\mathrm{nm})\end{array}$ & $\begin{array}{c}\mathrm{T} \% \\
(400 \mathrm{~nm})\end{array}$ & $\begin{array}{c}T_{\mathrm{d}}^{5} \\
\text { in N } \\
\left({ }^{\circ} \mathrm{C}\right)\end{array}$ & $\begin{array}{c}T_{\mathrm{d}}^{5} \\
\text { in air } \\
\left({ }^{\circ} \mathrm{C}\right)\end{array}$ \\
\hline PMDA $^{\mathrm{a})}$ & 342 & 55.0 & 0.008 & 2.78 & 1.27 & 2.08 & 37.6 & 330 & 85.5 & 464 & 390 \\
s-BPDA $^{\mathrm{a})}$ & 232 & 62.3 & 0.012 & 2.94 & 1.02 & 2.91 & 10.6 & 368 & 63.5 & 470 & 442 \\
$2,3,6,7-\mathrm{NTDA}^{2}$ & 376 & 45.2 & 0.034 & 2.96 & 0.97 & 2.15 & 20.7 & 385 & 73.3 & 465 & 403 \\
\hline
\end{tabular}

a) imidized at $250^{\circ} \mathrm{C} / 1 \mathrm{~h}+300^{\circ} \mathrm{C} / 1 \mathrm{~h}$ in vacuum on a substrate, then annealed at $305^{\circ} \mathrm{C} / 1 \mathrm{~h}$ in vacuum without substrate.

stretching effect (prohibited film contraction by substrates during thermal imidization). ${ }^{13}$ In the $4,4^{\prime}$ ODA systems, the water absorption decreased in the following order: PMDA/4,4'-ODA $(1.70 \%)>$ s-BPDA/4,4'-ODA $\quad(1.27 \%)>2,3,6,7-N T D A / 4,4^{\prime}-$ ODA $(1.16 \%)$. However, this trend differs partially from the order of the imide content: PMDA/ 4,4'-ODA $\quad(36.63 \mathrm{wt} \%)>2,3,6,7-\mathrm{NTDA} / 4,4^{\prime}$-ODA $(32.39 \mathrm{wt} \%)>\mathrm{s}-\mathrm{BPDA} / 4,4^{\prime}-\mathrm{ODA} \quad(30.55 \mathrm{wt} \%)$ in contrast to the APAB systems mentioned above.

Table $\mathrm{X}$ shows the comparison of the film properties between the MBCHAmix-based semi-cycloaliphatic PIs. It is interesting to note that, in spite of the use of MBCHA with a bent structure, the 2,3,6,7-NTDA/MBCHAmix polyimide film displayed a much lower CTE (45.2 ppm) than that of other MBCHA systems, emphasizing again how 2,3,6,7NTDA is a dianhydride monomer effective in obtaining lower CTE values. One notices that the water absorption decreased in the following order: PMDA/ MBCHA $(1.27 \%)>$ s-BPDA/MBCHA $(1.02 \%)>$ 2,3,6,7-NTDA/MBCHA $(0.97 \%)$ as well as the trend observed in the 4,4'-ODA systems. The red-shifted transmission spectra from the PMDA/MBCHA, s-BPDA/MBCHA, and to 2,3,6,7-NTDA/MBCHA film, which is represented as a shift of the cut-off wavelength from 330,368 , and to $385 \mathrm{~nm}$, are attributed to the extended $\pi$ electron conjugation from the pyromellitimide, biphenyldiimide, and to naphthaldiimide units.

\section{CONCLUSION}

2,3,6,7-NTDA showed high polymerizability with various aromatic and cycloaliphatic diamines with the exception of CHDA, whereas its isomer, 1,4,5,8NTDA did not. The poor reactivity of the latter is attributed to more stable six-membered anhydride structure. The PI films derived from 2,3,6,7-NTDA with various rigid diamines, PDA, APAB, TFMB gave no distinct glass transitions or a considerably high $T_{\mathrm{g}}$ exceeding $400^{\circ} \mathrm{C}$, extremely low CTE values, and relatively low degrees of water absorption at the same time in addition to excellent thermal stability. Even when flexible ether-containing 4,4'-ODA was used as a diamine component, the 2,3,6,7-NTDA-based PI film caused a low CTE $\left(20.0 \mathrm{ppm} \mathrm{K}^{-1}\right)$ closed to that of copper foil. In addition, the 2,3,6,7-NTDA/4,4'ODA polyimide film was highly tough as illustrated from its considerably high $\mathrm{E}_{\mathrm{b}}(>80 \%)$ and also showed a relatively low water absorption (1.16\%). The results revealed that 2,3,6,7-NTDA is a useful dianhydride monomer which provides unique PIs possessing lower CTE, lower water absorption, and higher $T_{\mathrm{g}}$, which are advantageous for FCCL applications.

\section{REFERENCES}

1. "Polyimides: Synthesis, Characterization and Application," K. L. Mittal, Ed., Plenum, New York, 1984. 
2. "Polyimide: Thermally Stable Polymers," M. I. Bessonov, M. M. Koton, V. V. Kudryavtsev, and L. A. Laius, Ed., Plenum, New York, 1987.

3. "Polyimides: Materials, Chemistry and Characterization," C. Feger, M. M. Khojasteh, and J. E. McGrath, Ed., Elsevier, Amsterdam, 1989.

4. "Advances in Polyimide Science and Technology," C. Feger, M. M. Khojasteh, and M. S. Htoo, Ed., Technomic, Lancaster, 1993.

5. "Polyamic acid and Polyimides: Synthesis, Transformation and Structure," M. I. Bessonov and V. A. Zubkov, Ed., CRC Press, Boca Ranton, FL, 1993.

6. "Polyimides: Fundamentals and Applications," M. K. Ghosh and K. L. Mittal, Ed., Marcel Dekker, New York, 1996.

7. "Polyimides: Trends in Materials and Applications," C. Feger, M. M. Khojasteh, and S. E. Molis, Ed., Society of Plastic Engineers, New York, 1996.

8. "Advances in Polyimides and Low Dielectric Polymers," H. S. Sachdev, M. M. Khojasteh, and C. Feger, Ed., Society of Plastic Engineers, New York, 1999.

9. "Polyimides and Other High Temperature Polymers: Synthesis, Characterization and Applications," vol. 1, K. L. Mittal, Ed., VSP, Zeist, The Netherland, 2001.

10. "The Latest Polyimides: Fundamentals and Applications," Y. Imai Y and R. Yokota, Ed., NTS, Tokyo, 2002. (in Japanese)

11. S. Numata, S. Oohara, K. Fujisaki, K. Imaizumi, and N. Kinjyo, J. Appl. Polym. Sci., 31, 101 (1986).

12. S. Numata, K. Fujisaki, and N. Kinjyo, Polymer, 28, 2282 (1987).

13. M. Hasegawa, T. Matano, Y. Shindo, and T. Sugimura, Macromolecules, 29, 7897 (1996).

14. J. C. Coburn and M. T. Pottiger, in "Polyimides: Fundamentals and Applications," M. K. Ghosh and K. L.
Mittal, Ed., Marcel Dekker, New York, 1996, p 207.

15. T. Kikuchi and T. Saito, Kagaku (Chemistry), 43, 668 (1988). (in Japanese)

16. A. Morikawa and K. Ono, High Perform. Polym., 13, S73 (2001).

17. M. Hasegawa and M. Koyanaka, High Perform. Polym., 15, 47 (2003).

18. M. Hasegawa and K. Koseki, High Perform. Polym., 18, 697 (2006).

19. Y. Yin, S. Chen, X. Guo, J. Fan, K. Tanaka, H. Kita, and K. Okamoto, High Perform. Polym., 18, 617 (2006).

20. Japanese Patent, JPH05-32779.

21. M. Hasegawa, High Perform. Polym., 13, S93 (2001).

22. M. Hasegawa and K. Horie, Prog. Polym. Sci., 26, 259 (2001).

23. M. Hasegawa, M. Horiuchi, and Y. Wada, High Perform. Polym., 19, 175 (2007).

24. Y. Oishi, K. Ogasawara, H. Hirahara, and K. Mori, J. Photopolym. Sci. Technol., 14, 37 (2001).

25. M. Hasegawa, Z. Shi, R. Yokota, F. He, and H. Ozawa, High Perform. Polym., 13, 355 (2001).

26. M. Hasegawa, N. Sensui, Y. Shindo, and R. Yokota, Macromolecules, 32, 387 (1999).

27. M. Hasegawa, N. Sensui, Y. Shindo, and R. Yokota, J. Polym. Sci., Part B: Polym. Phys., 37, 2499 (1999).

28. M. Hasegawa in "The Latest Polyimides: Fundamentals and Applications," Y. Imai Y and R. Yokota, Ed., NTS, Tokyo, 2002, p 101. (in Japanese)

29. P. Eiselt, S. Denzinger, and H-W. Schmidt, Liquid Crystals, 18, 257 (1995).

30. L. Vladimirov, M. Hasegawa, and R. Yokota, Network Polymers, 19, 18 (1998). (in Japanese)

31. S. Numata and T. Miwa, Polymer, 30, 1170 (1989).

32. M. Hasegawa, Polym. Prepr., Jpn., 50, 858 (2001). 